This item was submitted to Loughborough's Research Repository by the author.

Items in Figshare are protected by copyright, with all rights reserved, unless otherwise indicated.

\title{
Photovoltaic performance measurements in Europe: PV-catapult round robin tests
}

PLEASE CITE THE PUBLISHED VERSION

http://dx.doi.org/10.1109/WCPEC.2006.279955

PUBLISHER

(C) IEEE

VERSION

VoR (Version of Record)

LICENCE

CC BY-NC-ND 4.0

\section{REPOSITORY RECORD}

Betts, Thomas R., T. Zdanowicz, M. Prorok, W. Kolodenny, H. de Moor, N.V.D. Borg, D. Stellbogen, et al.. 2019. "Photovoltaic Performance Measurements in Europe: Pv-catapult Round Robin Tests". figshare. https://hdl.handle.net/2134/8218. 
This item was submitted to Loughborough's Institutional Repository (https://dspace.lboro.ac.uk/) by the author and is made available under the following Creative Commons Licence conditions.

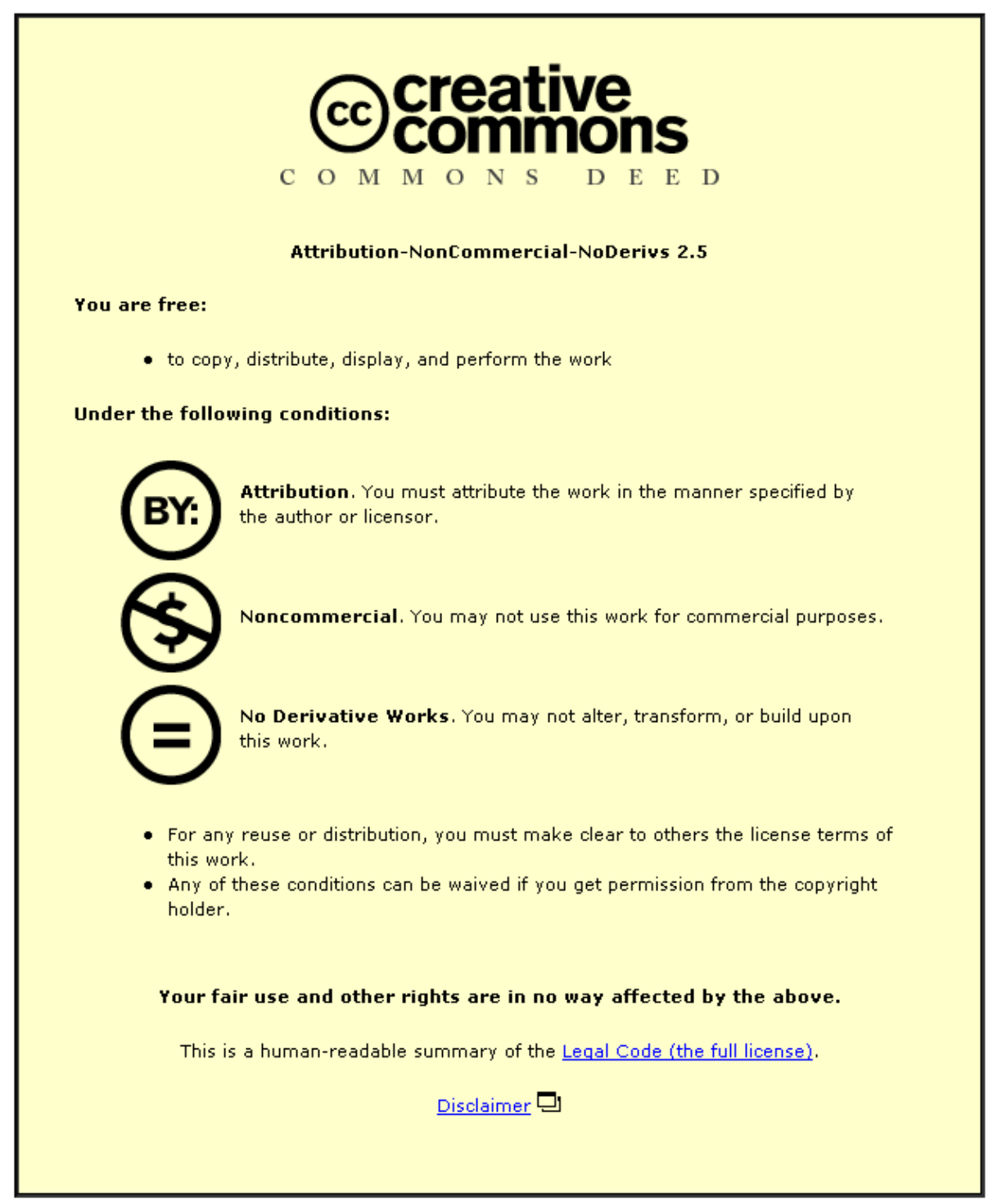

For the full text of this licence, please go to: http://creativecommons.org/licenses/by-nc-nd/2.5/ 


\title{
Photovoltaic Performance Measurements in Europe: PV-Catapult Round Robin Tests
}

\author{
T.R. Betts ${ }^{(1)^{*}}$, T. Zdanowicz ${ }^{(2) \dagger}, M$. Prorok $^{(2)}$, W. Kolodenny ${ }^{(2)}$, H. de Moor ${ }^{(3)}$, N. v.d. Borg ${ }^{(3)}$, D. Stellbogen ${ }^{(4)}$, \\ J. Hohl-Ebinger ${ }^{(5)}$, W. Warta ${ }^{(5)}$, G. Friesen ${ }^{(6)}$, D. Chianese ${ }^{(6)}$, A. Guerin de Montgareuil ${ }^{(7)}$, W. Herrmann ${ }^{(8)}$, \\ J. Diaz Berrade ${ }^{(9)}$, J. Moracho ${ }^{(9)}$, A.B. Cueli ${ }^{(9}$, A.R. Lagunas R ${ }^{(9)}$, R. Gottschalg ${ }^{(1)}$ \\ ${ }^{(1)}$ Centre for Renewable Energy Systems Technology, Loughborough University, UK; ${ }^{(2)}$ Wrocław University of \\ Technology, Wroclaw, Poland; ${ }^{(3)} \mathrm{ECN}$, Petten,NL; ${ }^{(4)} \mathrm{ZSW}$, Stuttgart, D; ${ }^{(5)}$ Fraunhofer Institute for Solar Energy Sys- \\ tems, Freiburg, D; ${ }^{6}$ SUPSI-LEEE, Cannobio, CH; ${ }^{7}$ CEA-GENEC, Caderache, FR; ${ }^{(8)}$ TÜV-Rheinland, Cologne, D; (9) \\ CENER, Sarriguren, ES
}

\begin{abstract}
Two sets of modules have been sent around to different testing installations across Europe, one set to laboratories performing indoor calibrations and one set to laboratories performing outdoor power and energy ratings. The results show that for crystalline and polycrystalline devices, a very good agreement between laboratories has been achieved. A lower agreement between laboratories has been achieved for thin film devices and further need for research is identified.
\end{abstract}

\section{INTRODUCTION}

The co-ordination action PV-Catapult, which is funded by the European Commission, aims to strengthen the European research area by furthering collaboration between different countries. As part of this project, a comparison of measurement approaches for indoor and outdoor calibration of photovoltaic devices has been set-up, which is reported upon here. This evaluation of the state of the art of different European research facilities will be the basis of an extended follow up programme.

This work was carried out in two steps, first a questionnaire was sent around to collect the specification of equipment and methodologies in use in the different labs and then two round-robin (RR) tests were set up, one for indoor measurement evaluation and one for outdoor measurement stations.

\section{ROUND ROBIN SETUP}

Two groups of five modules were sent around to the different laboratories for testing and data was pooled by Wroclaw for analysis by WrUT and CREST. Each group contained one module of the following categories: monocrystalline silicon (sc-Si), polycrystalline silicon (pc$\mathrm{Si}$ ), triple junction amorphous silicon (a-Si), CopperIndium,Galium-Diselenide (CIGS) and Cadmium Telluride $(\mathrm{CdTe})$. The modules in both batches were similar but not identical hence a direct comparison of the indoor and outdoor measurements cannot be achieved. These modules and their name-plate data are summarized in Table 1.

\begin{tabular}{|l|l|l|l|l|l|l|}
\hline Identifier & $\begin{array}{l}\text { Length } \\
{[\mathbf{m m}]}\end{array}$ & $\begin{array}{l}\text { Width } \\
{[\mathbf{m m}]}\end{array}$ & $\begin{array}{l}\boldsymbol{P}_{\text {MPP }} \\
{[\mathbf{W}]}\end{array}$ & $\begin{array}{l}\text { Voc } \\
{[\mathbf{V}]}\end{array}$ & $\begin{array}{l}\text { Isc } \\
{[\mathbf{A}]}\end{array}$ & $\begin{array}{l}\text { Eff } \\
{[\%]}\end{array}$ \\
\hline A60A & 1027 & 503 & 60 & 21 & 3,85 & 11,6 \\
\hline KC60A & 752 & 652 & 60 & 21,5 & 3,73 & 12,2 \\
\hline US32A & 1368 & 382 & 32 & 23,8 & 2,4 & 6,1 \\
\hline WS11007A & 1200 & 600 & 75,0 & 51,0 & 2,00 & 10,4 \\
\hline ATF43A & 1200 & 600 & 43,0 & 81,0 & 1,07 & 6,0 \\
\hline FS-50 & 1200 & 600 & 48,0 & 81,0 & 1,00 & 6.7 \\
\hline
\end{tabular}

Table 1: Overview of Modules and their name-plate data used in the RRs

At different stages during the shipping, two modules were damaged. The CdTe module for the outdoor testing had to be replaced and the triple junction in the outdoor batch obtained a marked indentation during transport, which has been shown to affect the measurements reported on later in this paper.

The indoor data is used as supplied by the test laboratories. For each outdoor RR module for each testing station, the I-V curve measured outdoors under conditions closest to Standard Test Conditions irradiance and module temperature was corrected to STC for intercomparison. The corrections were made by irradiance for the current and by temperature for the voltage, using the following translation equations:

$$
\begin{aligned}
I^{S T C} & =I^{M E A S}+\left[\left(\frac{1000}{G_{P O A}}\right)-1\right] \times I_{S C}^{M E A S} \\
V^{S T C} & =\left[\left(25-T_{M O D}\right) \times \frac{\beta}{100}+1\right] \times V^{M E A S}
\end{aligned}
$$

where $I^{S T C}$ and $V^{S T C}$ are the corrected values of the $I^{M E A S}$ and $V^{M E A S}$ current and voltage measurement points, $G_{P O A}$ is the measured in-plane irradiance in $\mathrm{W} / \mathrm{m}^{2}, T_{M O D}$ is measured module temperature and $\beta$ is the temperature coefficient of $\mathrm{V}_{\mathrm{OC}}$ in $\% /{ }^{\circ} \mathrm{C}$. The temperature dependence of current could not be included in this study since the data required to determine this tempera- 
ture coefficient were not possible to extract over the short measurement periods of this RR for all sites.

\section{PARTICIPATING SYSTEMS}

\section{Solar Simulators}

There is a multitude of different solar simulators in the test. There are one steady state simulator (SS1) and six flash simulators (FS1-FS6) manufactured by Berger (FS3), Endeas (FS6), Pasan (FS1,FS2 \& FS4) and Spire (FS5). Measurement approaches range from steady state, single flash to multi-flash with measurement durations between 2 and $10 \mathrm{~ms}$. Most of the simulators use the as purchase electronics, with FS2 having specifically designed electronics. No spectral correction was available as spectral information was not delivered.

\section{Outdoor Stations 1-6 (OS1-OS-6)}

All these systems are purpose built systems, but not of any commercial manufacturer. The data used for analysis here is from the centralized collection, which uses the thermopile pyranometer measurement for irradiance, it should be noted that each lab also carried out their own analysis which varied slightly from the centralized one, but overall the trends are similar. It is expected that the analysis by the different stations will yield an even better agreement, given the increased level of understanding of the specific measurement systems.

A more detailed analysis of these systems will be published later this year on the $21^{\text {st }}$ European Photovoltaic Solar Energy Conference.

\section{RESULTS}

All modules were tested in the steady state solar simulator at the beginning and end of the RR. The average of these measurements is taken as the base-line in this report. The difference between these two measurements is shown in Figure 1.

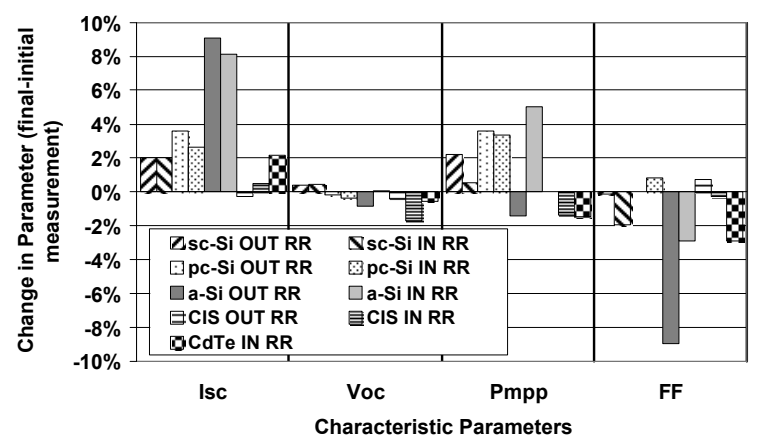

Figure 1: Variations of the module parameter during the RRs

All modules agree within two percent except for the a-Si, CdTe and pc-Si modules. The a-Si modules have a significant deviation in the short circuit current, which is due to the procedure employed to measure these multijunction devices: the $I_{S C}$ is calibrated outdoors, in order to minimize the effect of spectral discrepancies between the solar simulator spectrum and the AM1.5 required for calibration. The lamp power is then regulated to give the same Isc. The initial measurement was carried out in a different season to the final one, which resulted in differences in the ISc calibration, and it was noted that the standard deviation of the linear fit during the initial measurements was higher than what normally would be acceptable, but had to be accepted due to the rigorous time constraints. The reduction in the FF of the outdoor a-Si module is due to the transportation damage mentioned above. No particular explanation was found for the other modules outside the two percent range.

The first sample to be analysed is the high capacitance sc-Si sample. The measurements of the accredited laboratories have an agreement better than $2 \%$ with respect to the average. The research laboratories have a much more significant problem with calibrating these devices. One (FS-5) overestimates the power by $11 \%$ which largely is due to the overestimation of $I_{S C}$ (due to a lack of a matched reference cell and building work related dust) and the overestimation of $\mathrm{V}_{\mathrm{OC}} / \mathrm{FF}$ (which is due to the lack of temperature control, which could not be corrected as no T-coefficient is known for this device). FS-6 also seems to suffer from a mismatched reference device, which explains the Isc variation. This laboratory also has the fastest data acquisition time, which explains the deviations in $\mathrm{V}_{\mathrm{OC}}$ and FF, as noticeable effects of the capacitance are experienced.
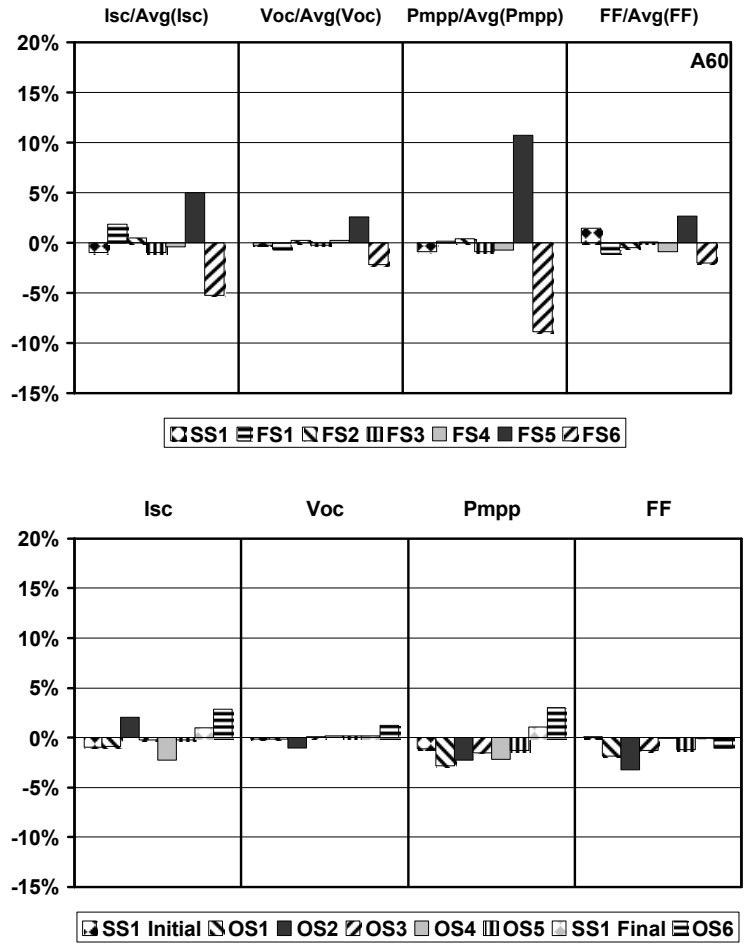

Figure 2: Agreement for the sc-Si sample (top indoor, bottom outdoor round robin)

Surprisingly, the variation between the outdoor laboratories is of equal quality to that of the steady state simulator, the standard deviation of all measurements is similar to that of the initial/final measurements. The most significant variation in the power measurements of OS1 and OS6 which measured late spring and winter respectively, which could explain the difference especially in Isc. The curves taken for analysis are the ones closest to 
STC, which means for OS1 that it will not be noon (early morning had sufficient irradiance and lower device temperatures) and thus reflection will be slightly higher, while OS6 will have had virtually perfect perpendicular angle of incidence to get anywhere near STC. There is one item of note for OS2, which in most cases estimates a higher than average Isc but also a lower than average FF. This is not an artifact of the measurement system but of the way the data is stored: This station logs the P$\mathrm{V}$ curve rather than the I-V curve as the other stations. This means that there is a small round off error when the currents for low powers are extracted, which then propagates into the determination of the Isc. This high estimation then results in an underestimation of FF. The directly measured points $V_{O C}$ and $P_{M P P}$ are virtually identical with the average of all the others.

The agreement is even better for the pc-Si devices, as illustrated in Figure 3. FS-5 has the same problems as before but to a lower extent, which reduces the difference to the average in the power measurements to less than $6 \%$, FS6 is virtually on the average of all measurements. There is a slight variation in the $I_{s c}$ of about four percent, which is due to different reference cells being used.

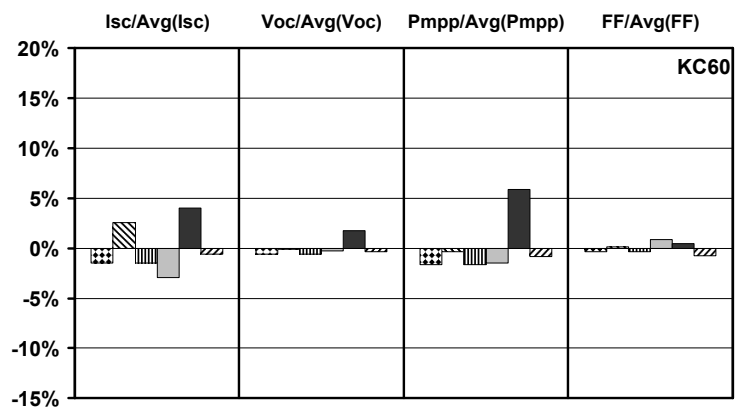

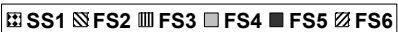

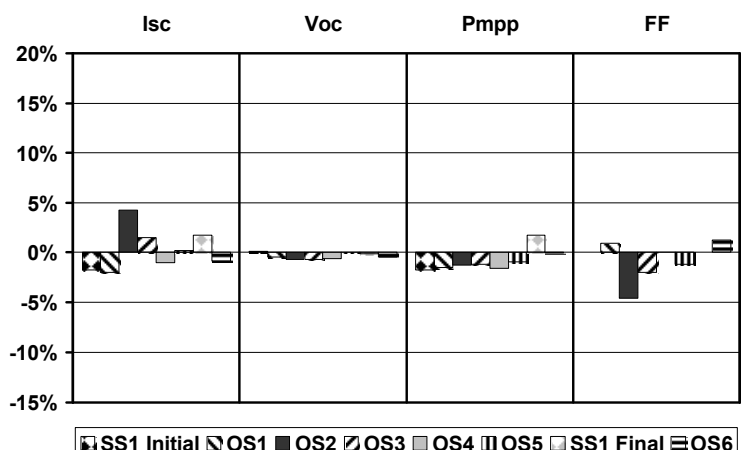

Figure 3: Agreement for the pc-Si sample (top indoor, bottom outdoor round robin)

The agreement of outdoor measurements in the $I_{S C}$ is slightly better than that of the accredited solar simulators, which is slightly surprising because broadband measurements were used for the calibration. All power calibrations are within $\pm 2 \%$.

The picture changes for the CIGS sample, which has a relatively strong pre-conditioning effect on the measurement. It should be noted that this is not affecting the performance in realistic conditions, it is simply an added complication for the absolute calibration process. CIGS is the material with the least dependence on the spectrum, which shows in the best agreement of the indoor Isc determined, as shown in Figure 4. There is a very drastic difference between the flash simulators and the steady state simulator, in the FF and $\mathrm{V}_{\mathrm{OC}}$ and subsequently the $\mathrm{P}_{\mathrm{MPP}}$ determination. This is a direct expression of the preconditioning, which can only be carried out correctly in a steady state solar simulator and thus this result can be seen as the most reliable. All other labs underestimate the power by as much as $10 \%$, depending on how long the samples had been stored in darkness before measurement.
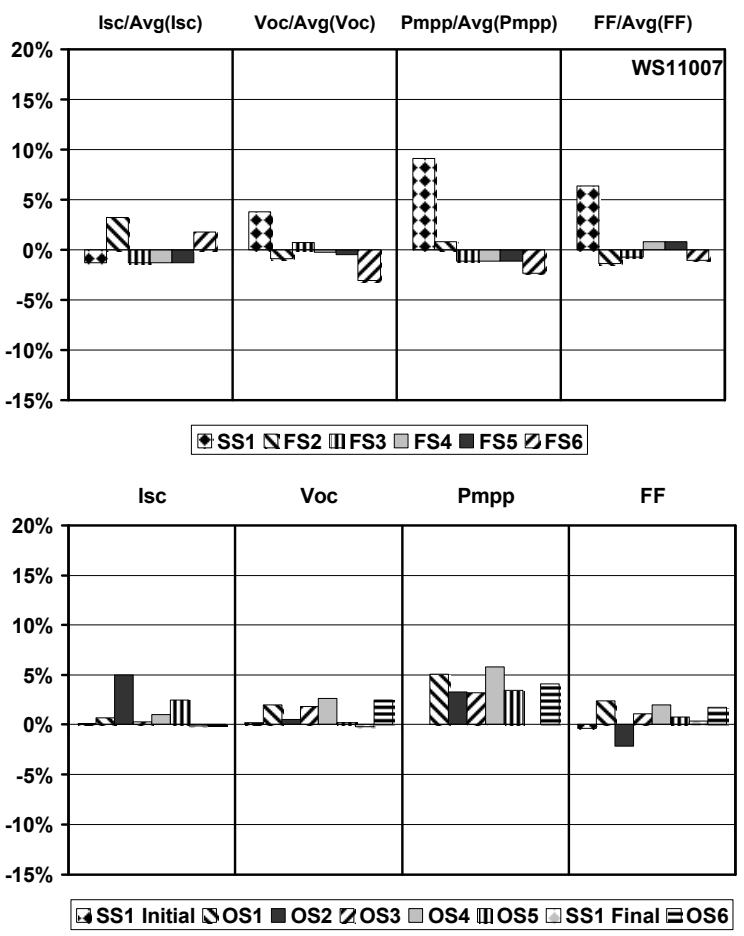

Figure 4: Agreement for the CIGS sample (top indoor, bottom outdoor round robin)

This pre-conditioning is less of an issue for the outdoor test installations, and subsequently all laboratories actually measure the power higher than the average of the steady state simulator measurements. There is a slight difference between the laboratories which have their modules open circuited between the measurements and the laboratories which MPPT between measurements (OS1 \& OS4) - the latter measure slightly higher power. Nevertheless, the variation of the power calibration between the outdoor laboratories is better than $\pm 1.5 \%$.

The CdTe sample is a wide band gap device, which shows the expected variation in the short circuit current of different lamp sources, as shown in Figure 5. The high estimation of ISC by FS6 is somewhat negated by the low measurement of the FF, which in the end results in an agreement of the power calibration of $\pm 2.75 \%$.

The agreement of the power calibration demonstrates the same variation as the indoor calibration $( \pm 2.75 \%)$. The short circuit current is measured gener- 
ally higher than in the indoor measurements, as well as the $\mathrm{V}_{\mathrm{OC}}$, while the FF is underestimated.
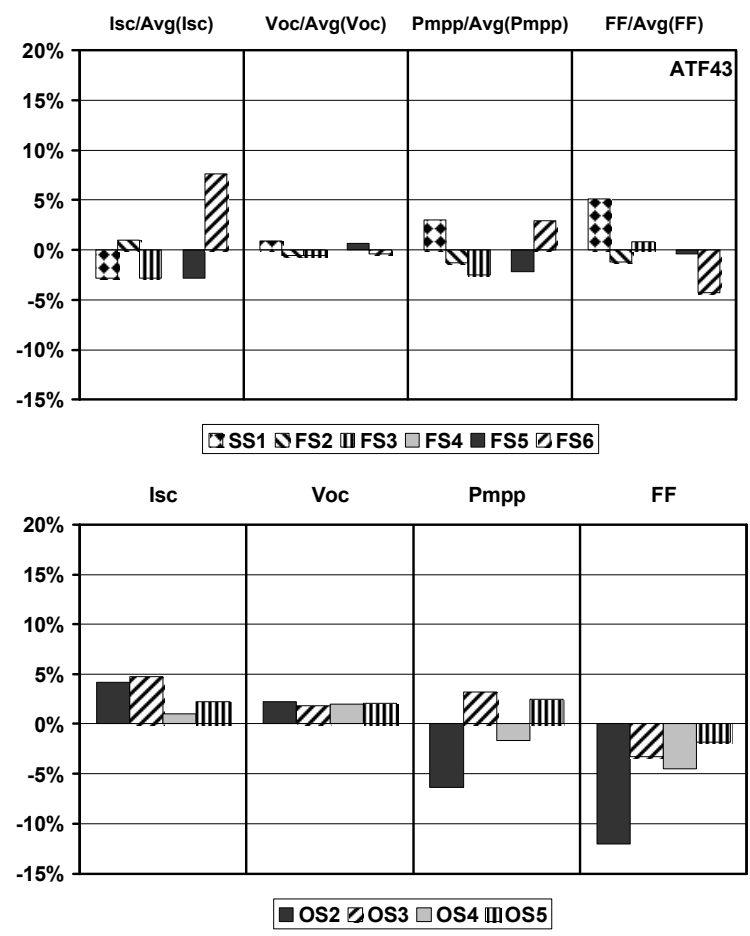

Figure 5: Agreement for the CdTe sample (top indoor, bottom outdoor round robin)

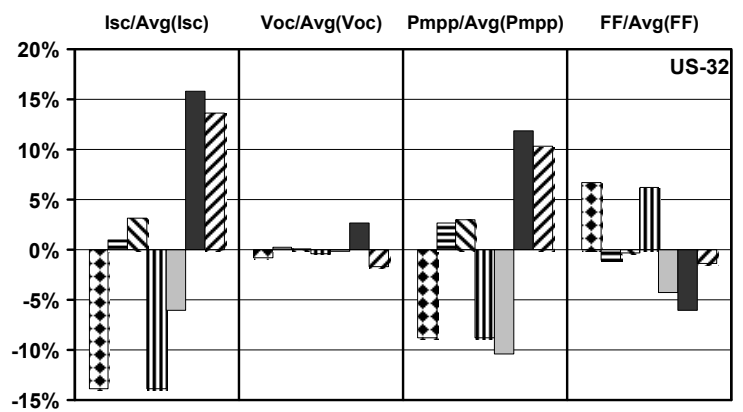

QSS1 EFS1 DFS2 IIFS3 $\square$ FS4 IFS5 ZFS6

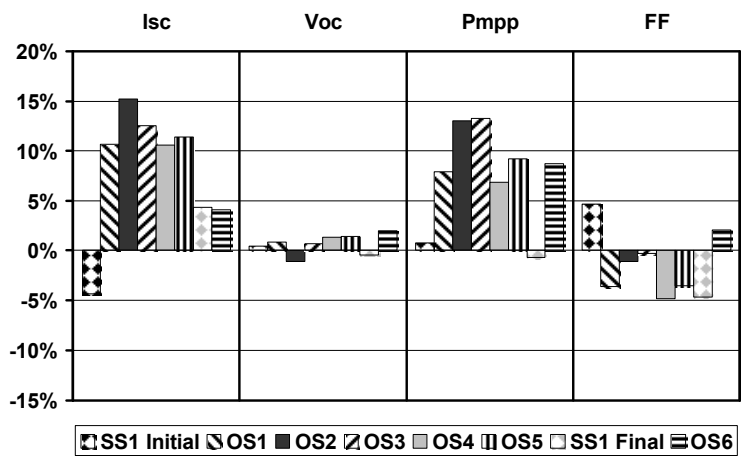

Figure 6: Agreement for the a-Si sample (top indoor, bottom outdoor round robin)

Probably the most difficult device to calibrate is the triple junction device. The most significant effect is, as shown in Figure 6, in the short circuit current. There will be a strong seasonal and weather dependence. Two systems (SS1, FS3) yield short circuit currents which are nearly $15 \%$ lower than the average, while two overestimate the power by the same amount FS5, FS6). This is then directly observed in the power measurements, with the FF somewhat negating the discrepancies. The systems measuring a low ISc measure a high FF, while the systems measuring a high Isc measure a low FF. This may be an effect of mismatched junctions within the triple junction ('shaded' systems tend to have higher FF). The disagreement between the accredited laboratories is in the order of $14 \%$, which is the largest between all laboratories.

The agreement between the outdoor stations is actually better than that between the indoor test stations. It is better than $\pm 4.25 \%$ in the $I_{\text {sc }}$ and better than $\pm 3.5 \%$ of the power calibration. The difference in the $I_{S C}$ is an effect of the seasonal variation of the spectral content of the incident irradiance. Surprisingly, given that all the systems are non-commercial, self-developed units the confidence limit for multijunctions seems to be narrower than for industrial equipment. This could be because the outdoor solar spectrum associated with data selected on the condition of irradiance close to $1000 \mathrm{Wm}^{-2}$ is always closer to the AM1.5 standard than most solar simulator light sources. Thus the problems of appropriately matching the sub-cells is less of an issue.

\section{CONCLUSIONS}

Two round robins have been carried out throughout a number of European laboratories. It is clear that in the case of industrially available equipment (solar simulators), the methodology is absolutely crucial. Having good equipment alone does not guarantee a narrow uncertainty limit. The measurement agreement of the $\mathrm{c}-\mathrm{Si}$ devices is very good between all accredited laboratories. The slightly less experienced laboratories using their equipment for research purposes are having to improve their methodology to match the accuracy of the accredited laboratories. The reference cell is absolutely crucial for accurate calibrations, even more so for samples with high band gaps (and thus narrow spectral response) and multi-junction devices. There is a clear need for further improvement in the treatment of thin film devices, to get a better agreement between the laboratories.

A rather surprising agreement has been found between the different outdoor test facilities. Although all these systems are one-off designs and much less established than commercial solar simulators, the agreement between the laboratories based on a simple and nonspecific approach, has been shown to be very good, with much reduced PV technology-related problems encountered. Thin-film devices will need to be researched in more detail, especially the effects of different operating strategies between the I-V measurements used for calibration purposes (i.e. open circuiting, MPPT or short circuiting), as some devices seem to have a dependence on this.

\section{ACKNOWLEDGEMENTS}

This work was funded through the European Commission as part of the co-ordination action PV-Catapult (Grant No: 502775 (SES6)). 